\title{
Bilateral en-masse distalization of maxillary posterior teeth with skeletal anchorage: a case report
}

\author{
Saeed Noorollahian¹, Shiva Alavi², Farinaz Shirban³
}

DOI: http://dx.doi.org/10.1590/2177-6709.21.3.085-093.oar

Objective: The aim of this study was to introduce a new method for bilateral distal movement of the entire maxillary posterior segment. Case report: A 17-year-old girl with Class I skeletal malocclusion (end-to-end molar relationships, deviated midline and space deficiency for left maxillary canine) was referred for orthodontic treatment. She did not accept maxillary first premolars extraction. A modified Hyrax appliance (Dentaurum Ispringen, Germany) was used for bilateral distalization of maxillary posterior teeth simultaneously. Expansion vector was set anteroposteriorly. Posterior legs of Hyrax were welded to first maxillary molar bands. All posterior teeth on each side consolidated with a segment of $0.017 \times 0.025$-in stainless steel wire from the buccal side. Anterior legs of Hyrax were bent into eyelet form and attached to the anterior palate with two mini-screws $(2 \times 10 \mathrm{~mm})$ (Jeil Medical Corporation Seoul, South Korea). Hyrax opening rate was $0.8 \mathrm{~mm}$ per month. Lateral cephalometric radiographs were used to evaluate the extent of distal movement. 3.5-mm distalization of posterior maxillary teeth was achieved in five months. Results: A nearly bodily distal movement without anchorage loss was obtained. Conclusion: The mini-screw-supported modified Hyrax appliance was found to be helpful for achieving en-masse distal movement of maxillary posterior teeth.

Keywords: Hyrax. Orthodontics. Tooth movement.

Objetivo: o objetivo do presente estudo foi apresentar um novo método para a distalização bilateral de todo o segmento posterior superior. Relato do caso: uma jovem de 17 anos de idade, com má oclusão esquelética de Classe I (relação de molares em topo a topo, linha média desviada e deficiência de espaço para o canino superior esquerdo) foi encaminhada para tratamento ortodôntico, mas recusou-se a autorizar a extração dos primeiros pré-molares superiores. Um aparelho Hyrax modificado (Dentaurum, Ispringen, Alemanha) foi utilizado para a distalização bilateral simultânea dos dentes posteriores superiores. O vetor de expansão foi definido no sentido anteroposterior. As barras de conexão posteriores do Hyrax foram soldadas às bandas dos primeiros molares superiores. Em cada um dos lados, todos os dentes posteriores foram agrupados com um segmento de fio de aço inoxidável de calibre 0,017 " x 0,025" passando por vestibular. As barras de conexão anteriores do Hyrax foram dobradas em forma de loop e conectadas à região anterior do palato por meio de dois mini-implantes $(2 \mathrm{x} 10 \mathrm{~mm})$ (Jeil Medical Corporation, Seoul, Coreia do Sul). A taxa de abertura do Hyrax foi de $0,8 \mathrm{~mm} / \mathrm{mês}$. Telerradiografias laterias foram usadas para avaliar a extensão dos movimentos de distalização. Resultados: em um prazo de cinco meses, foi obtida uma distalização de 3,5mm dos dentes posteriores superiores. O movimento realizado foi praticamente de corpo (translação), sem qualquer perda de ancoragem. Conclusão: o aparelho Hyrax modificado suportado por mini-implantes mostrou-se útil para efetuar o movimento de distalização em massa dos dentes posteriores superiores.

Palavras-chave: Hyrax. Ortodontia. Movimento dentário.

${ }^{1}$ Assistant Professor, Isfahan University of Medical Sciences, Dental Implants Research Center, Department of Orthodontics, School of Dentistry, Isfahan, Iran.

${ }^{2}$ Associate Professor, Isfahan University of Medical Sciences, Dental Materials Research Center, Department of Orthodontics, School of Dentistry, Isfahan, Iran.

${ }^{3}$ Assistant Professor, Isfahan University of Medical Sciences, Torabinejad Dental Research Center, Department of Orthodontics, School of Dentistry, Isfahan, Iran.

Submitted: August 21, 2015 - Revised and accepted: September 14, 2015
How to cite this article: Noorollahian S, Alavi S, Shirban F. Bilateral en-masse distalization of maxillary posterior teeth with skeletal anchorage: a case report. Dental Press J Orthod. 2016 May-June;21(3):85-93.

doi: http://dx.doi.org/10.1590/2177-6709.21.3.085-093.oar

» The authors report no commercial, proprietary or financial interest in the products or companies described in this article.

» Patients displayed in this article previously approved the use of their facial and intraoral photographs.

Contact address: Farinaz Shirban

E-mail: shirban123@yahoo.com 


\section{INTRODUCTION}

Arch-length deficiency is a common problem in Orthodontics. We have two choices to manage this discrepancy: arch expansion or tooth mass reduction. ${ }^{1}$ When space deficiency is combined with missing or previous extracted teeth and a tendency towards molar Class II relationship, the first choice for providing space and solve the problem is distal movement of posterior teeth. This option is also recommended for patients who have space deficiency, but refuse tooth extraction.

Traditional techniques for molar distalization are extraoral traction, ${ }^{2,3}$ Cetlin removable plate, ${ }^{4,5}$ Wilson arches ${ }^{6}$ and First Class Appliance (Leone, Firenze, Italy) with continuous force delivered by springs, which counterbalances the action of buccal screws. ${ }^{7,8}$ All these distalizing appliances rely partially or totally on patient's cooperation.

Different sources of force were used for distal driving: repelling magnets, ${ }^{9,10}$ coil springs, looped NiTi wires, ${ }^{11}$ super-elastic nickel-titanium arch wires ${ }^{12}$ coil springs on a sectional arch wire (Jones Jig assembly, ${ }^{13,14,15}$ distal jet $^{16-18}$ and Keles slider ${ }^{19}$ ) springs in beta titanium alloy (pendulum appliance, ${ }^{15,20,21} \mathrm{~K}-\mathrm{loop}^{22}$, Intraoral Bodily Molar Distalizer Pendulum (IBMB), ${ }^{23}$ expansion screws (Modified Pendulum Appliance ${ }^{24}$ and Frog Appliance ${ }^{25}$ ).

Routine anchorage units used in these appliances are other teeth or palatal acrylic pad. ${ }^{26}$ Recently, bone-borne appliances, such as dental implants, ${ }^{27}$ fixation mini-plates ${ }^{28}$ and orthodontic mini-screws ${ }^{29-33}$ have become widely used as anchorage system; for instance, Graz implantsupported pendulum appliance, ${ }^{28}$ bone-anchored pendulum appliance, ${ }^{29-32}$ a mini-screw implant-supported distalization system (MISDS), ${ }^{33}$ the ZGA (Zygoma-Gear Appliance) anchorage system for buccal segment distalization, ${ }^{34,35,36}$ dual-force distalizer supported by miniimplants (DFD), ${ }^{37}$ mesialy extended TPA (ME-TPA) with skeletal anchorage, ${ }^{38}$ the Keles Slider appliance with a palatal implant ${ }^{39}$ and timely relocation of mini-implants for uninterrupted full-arch distalization (jig). ${ }^{40}$

The aim of this report was to introduce a new method for simultaneous bilateral distalalization of the entire maxillary posterior segment.

\section{DIAGNOSIS}

A 17-year-old female patient visited the orthodontic department of Isfahan University of Medical Sciences. Her chief complaint was malposition of anterior teeth. She did not have any medical problems or active periodontal disease. The patient had a symmetrical, mesoprosopic and balanced face and a mild convex profile. (Fig 1). Intraoral examination revealed buccally displaced maxillary left canine, 3.5-mm upper midline deviation to the left and end-to-end molar relationship (Fig 2). Cephalometric analysis revealed no skeletal discrepancy.

\section{TREATMENT ALTERNATIVES}

Two treatment options were proposed to the patient:

1) Extraction of maxillary first premolars.

2) Distalization of the entire posterior segment.

The patient preferred the second treatment option.

\section{TREATMENT PROGRESS}

Treatment process began after extraction of maxillary third molars. A modified Hyrax appliance (Dentaurum Ispringen, Germany) was used for bilateral distalization of maxillary posterior teeth, simultaneously. The expansion vector was set anteroposteriorly. Posterior legs of Hyrax were welded to first maxillary molar bands. All posterior teeth on each side consolidated with a segment of $0.017 \times 0.025$-in stainless steel wire from the buccal side. Anterior legs of Hyrax were bent into eyelet form and attached to the anterior palate with two miniscrews $(2 \times 10 \mathrm{~mm})$ (Jeil Medical Corporation, Seoul, South Korea) (Fig 3). Hyrax opening rate was $0.8 \mathrm{~mm}$ per month. Lateral cephalometric radiographs were used to evaluate the extent of distal movements.

The stability of the appliance, mini-screws and oral hygiene were evaluated at each one of the monthly appointments. After five months, Class I relationship in molars and premolars was obtained. Post-distal driving intraoral view is seen in Figure 4. Cephalometric analysis was carried out to assess changes of molar position, inclination, mandibular plane angle and mini-screw inclination alternations. 

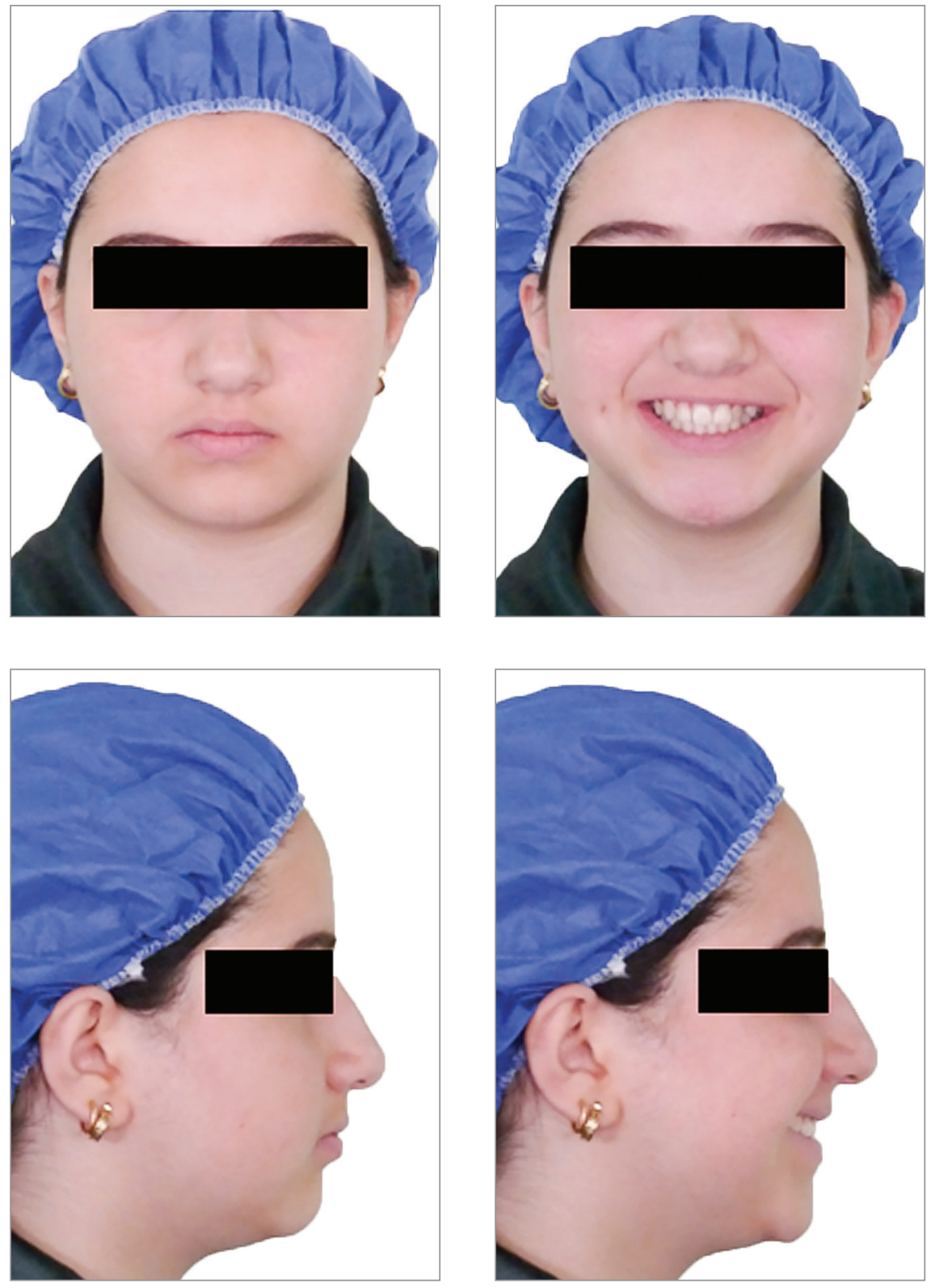

Figure 1 - Pretreatment extraoral photographs.
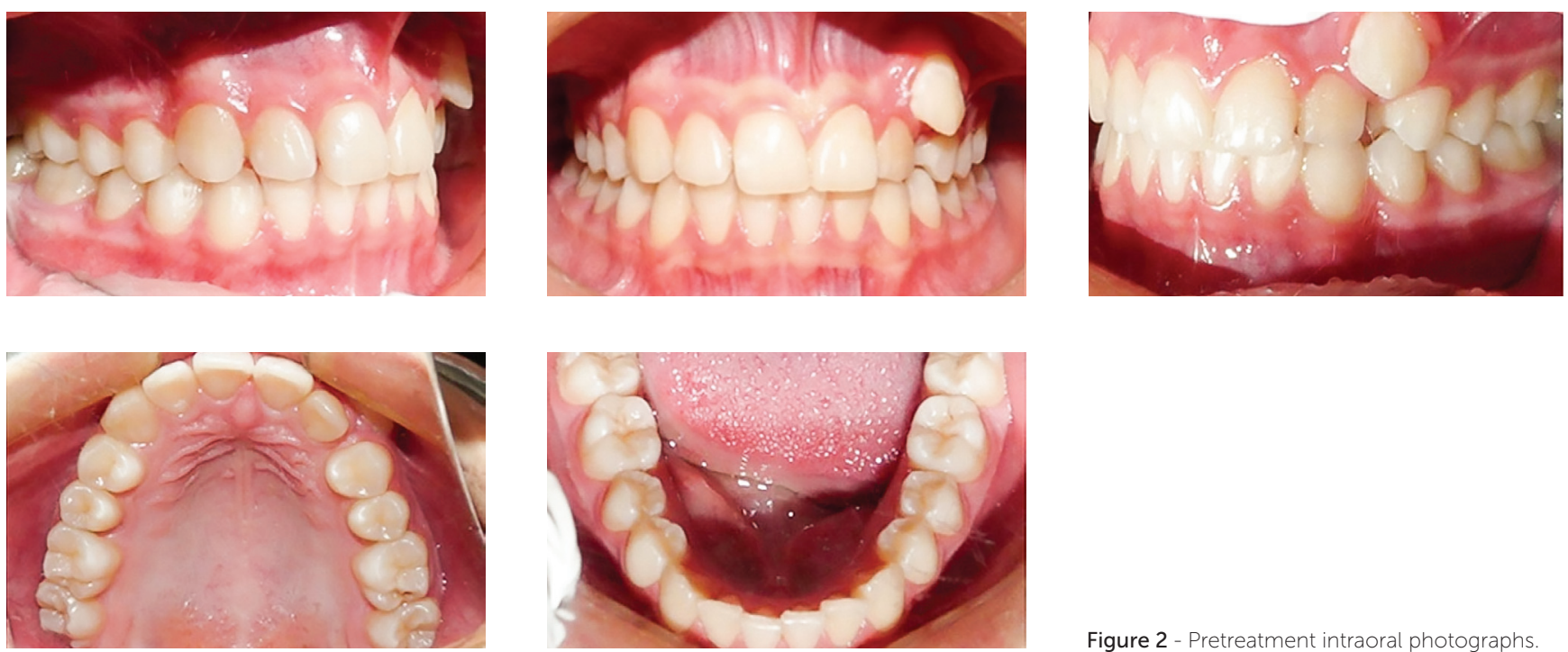

Figure 2 - Pretreatment intraoral photographs. 

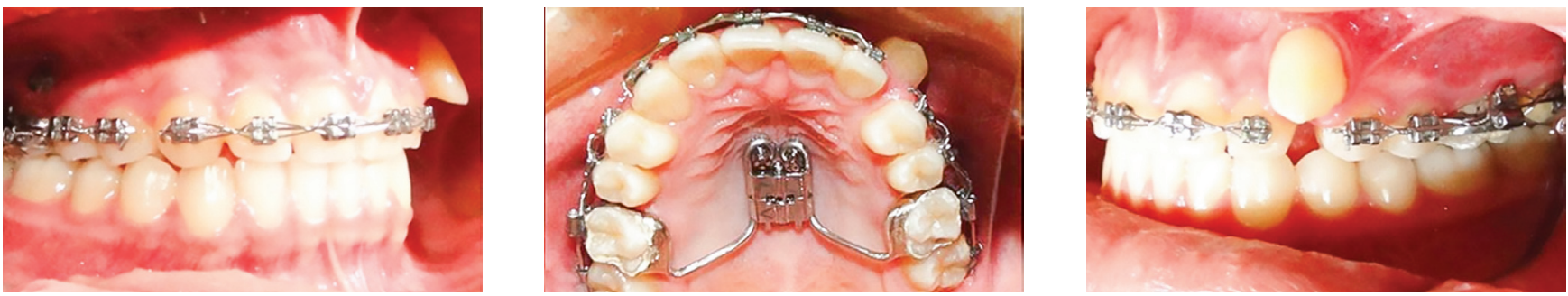

Figure 3 - Pre-distal driving intraoral photographs.
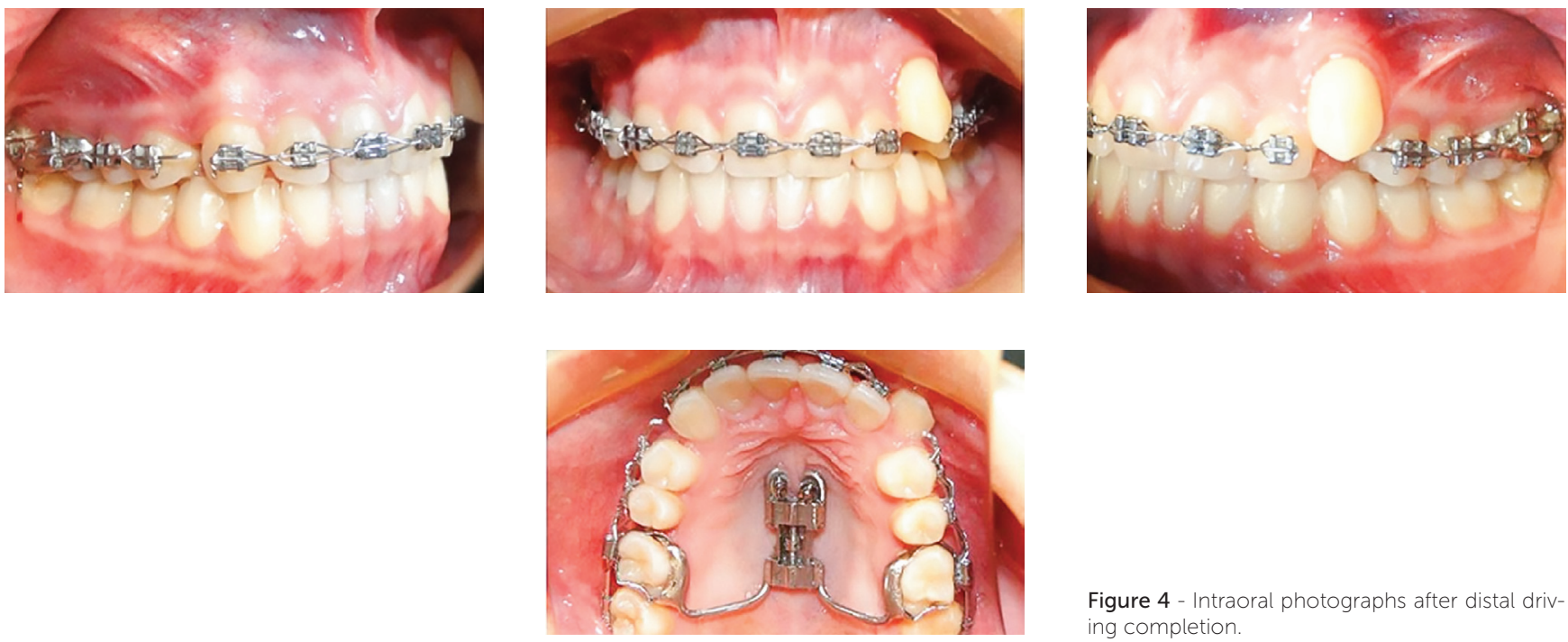

Figure 4 - Intraoral photographs after distal driving completion.

\section{TREATMENT RESULTS}

Figures 5 and 6 show the final outcomes after 15 months of orthodontic therapy. Buccally displaced maxillary left canine was corrected by using the space resulting from distal driving on the left side and midline correction by using the space resulting from distal driving on the right side. Molar and canine relationship was corrected, Class I was achieved and midline improved.

Figures 7 and 8 show pre-distal driving, post-distal driving and post-treatment cephalometric radiographs and tracings, and Table 1 shows the respective values.
To measure molar distalization, the most occlusal point on the distal cusp of the first molar was located, and its distance to a perpendicular line drawn from $\mathrm{Na}$ to the occlusal plane, used as a vertical reference, was assessed (Fig 8).

The changes of angle between the distal line angle of second molar and SN were assessed as molar inclination changes. Changes between the mandibular plane angle and Frankfort plane as well as Na-Menton distance were measured as vertical changes (Table 1 ).

The 16-month follow-up after distal driving is seen in Figure 9. 

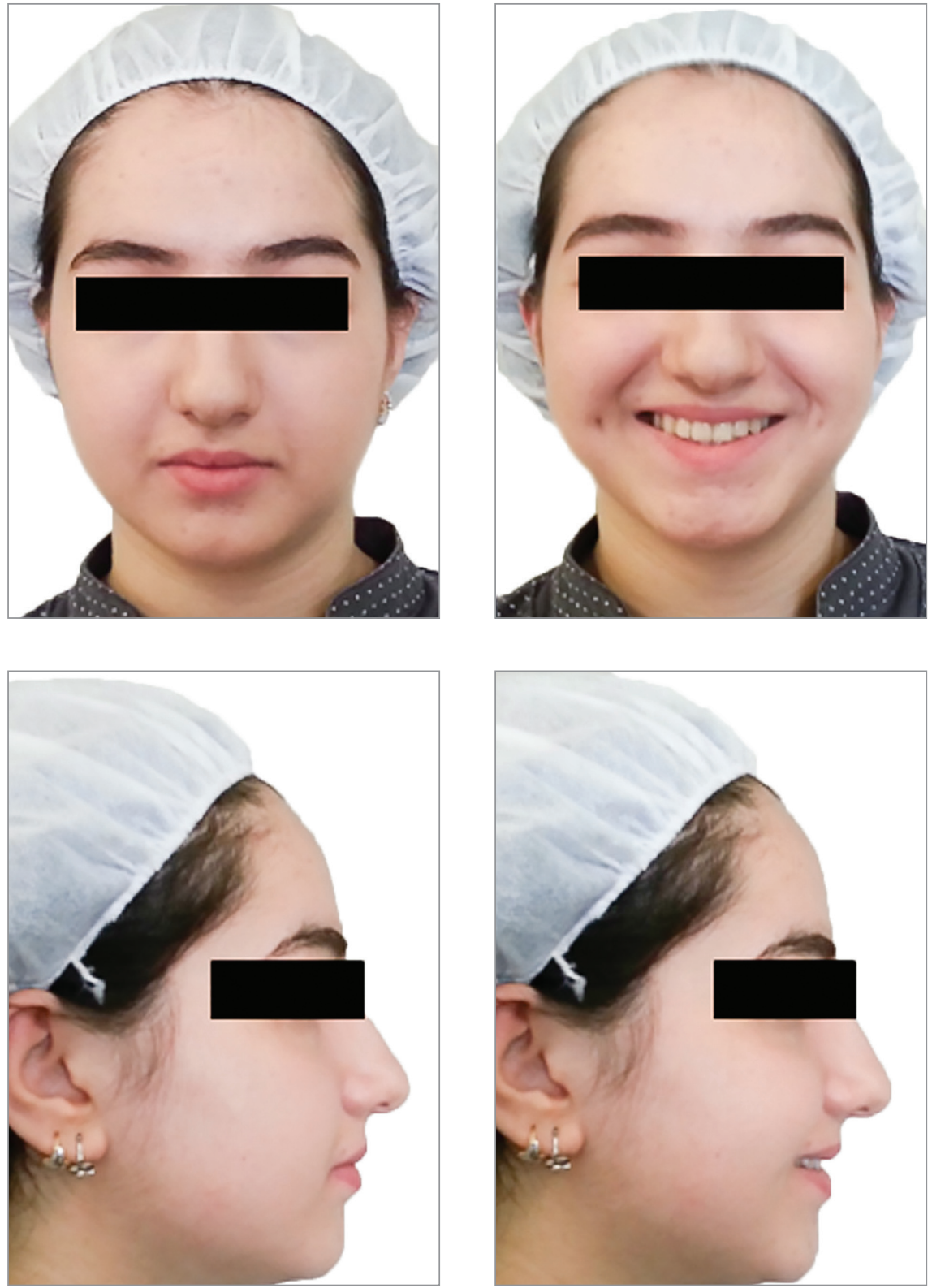

Figure 5 - Post-treatment extraoral photographs.
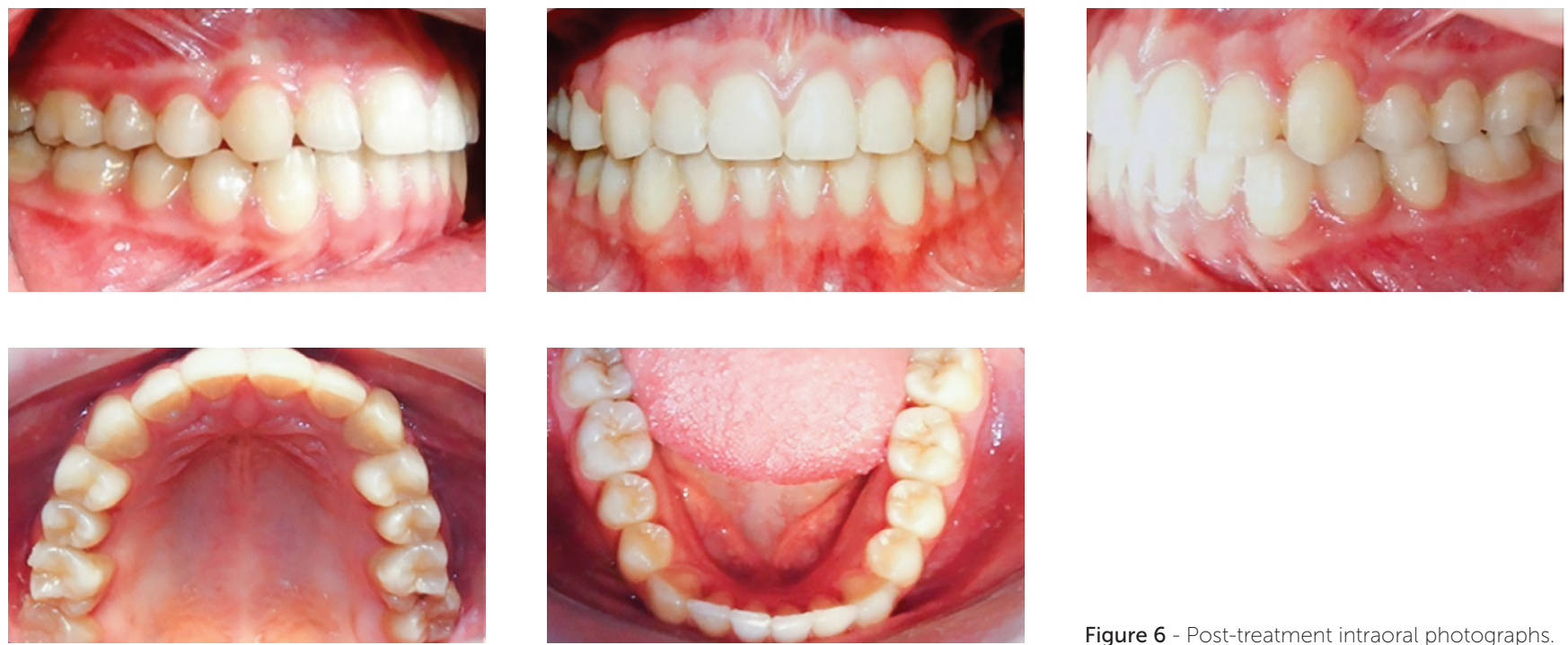

Figure 6 - Post-treatment intraoral photographs. 

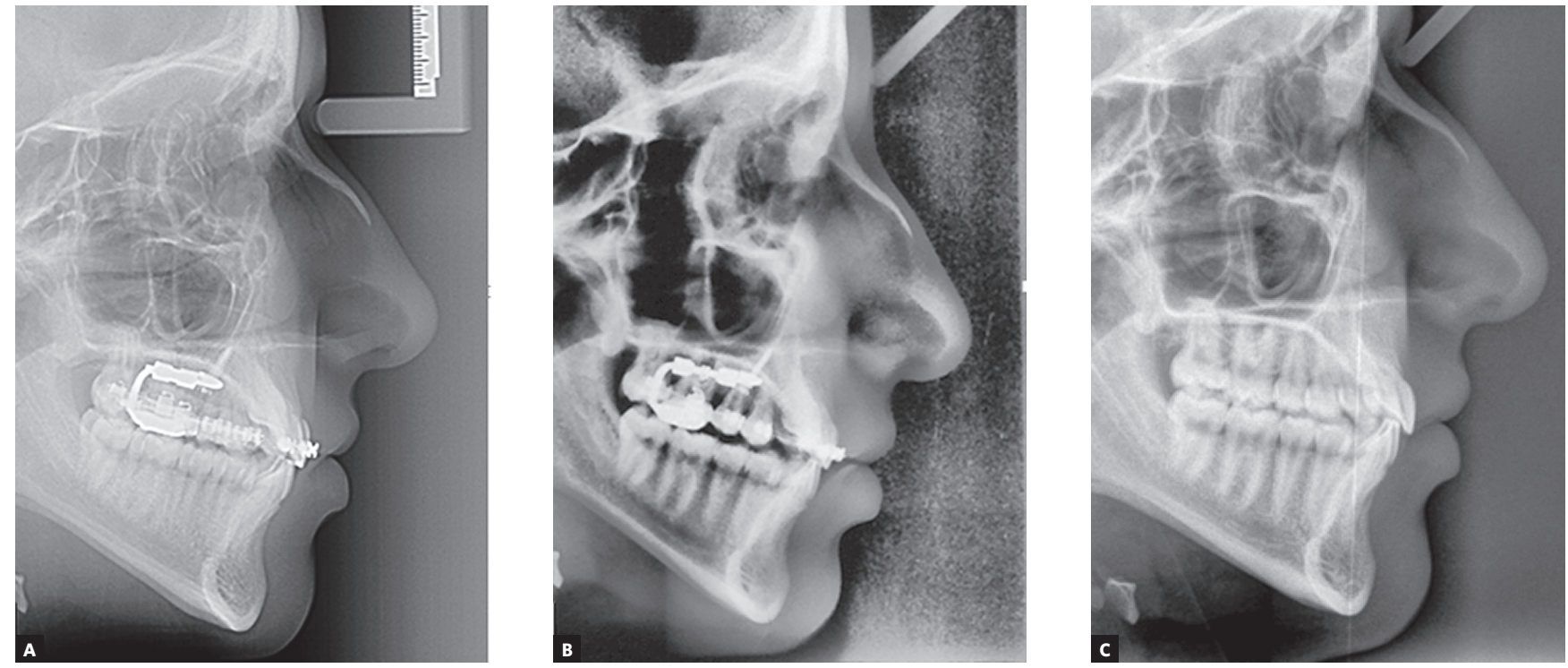

Figure 7 - A) Pre-distal driving lateral cephalometry. B) Post-distal driving lateral cephalometry. C) Post-treatment lateral cephalometry.

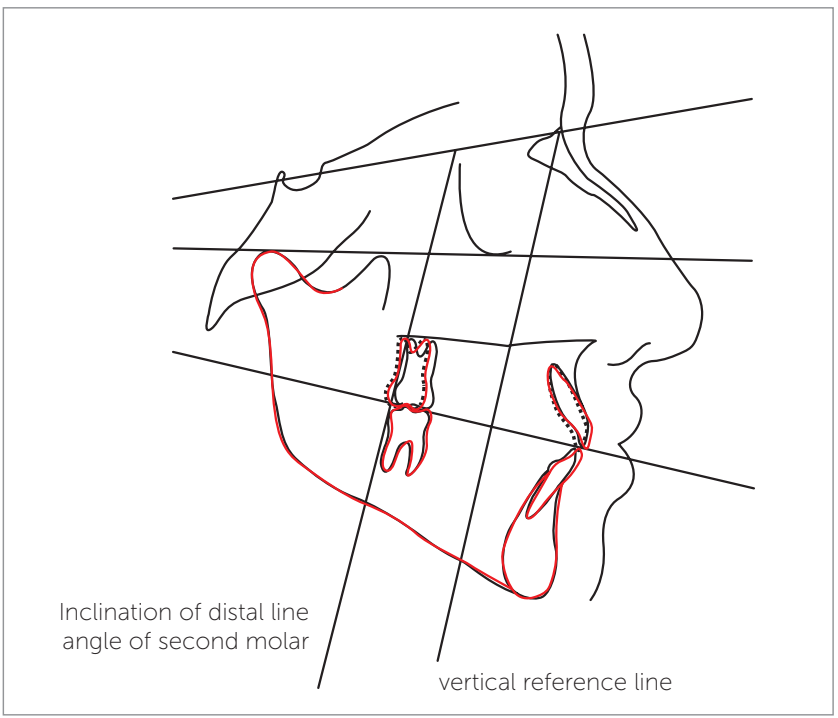

Figure 8 - Pre- (black line) and post- (dash line) distal driving and posttreatment (red line) lateral cephalometry superimpositions on S-Na.
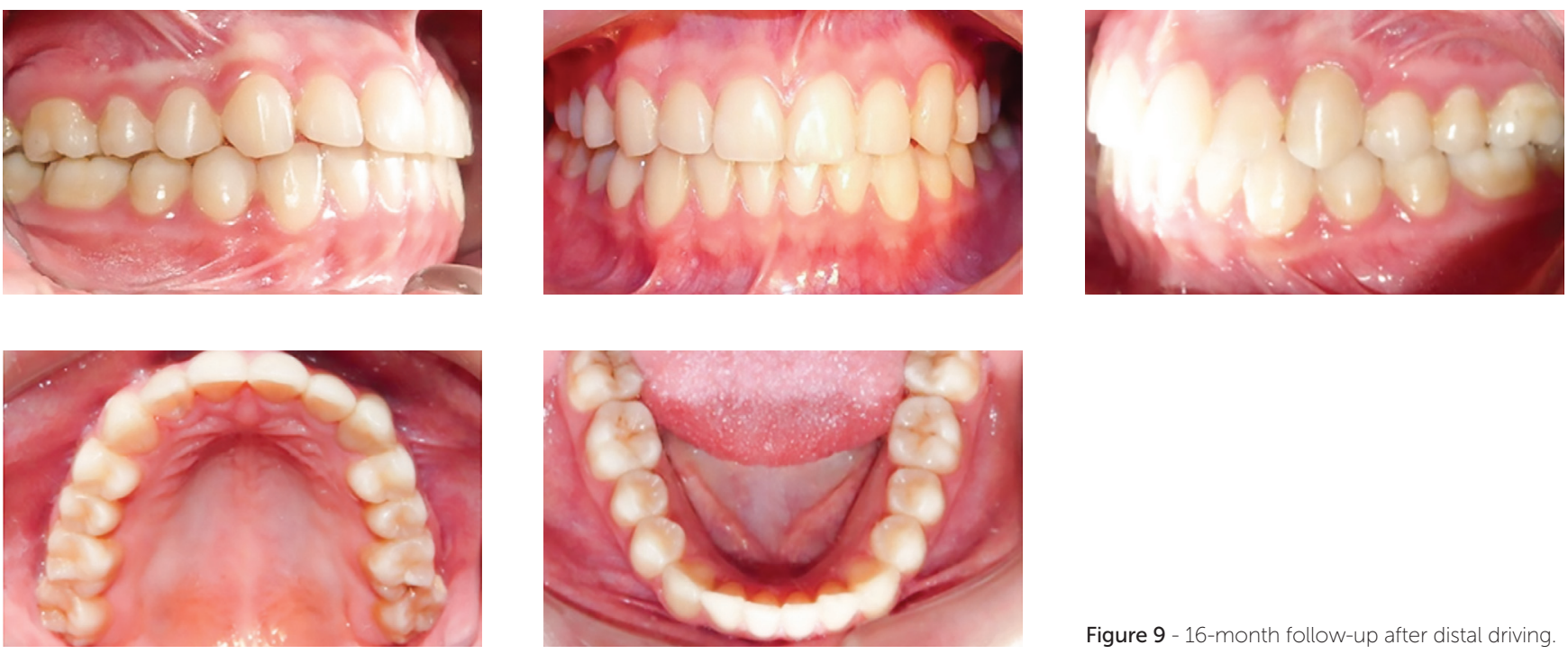

Figure 9 - 16-month follow-up after distal driving 
Table 1 - Cephalometric comparisons before and after distal driving and post-treatment.

\begin{tabular}{lcc}
\hline & Pre distal driving & Post distal driving \\
\hline SN-FH (degrees) & 11 & 11 \\
\hline SNA (degrees) & 83.5 & 83.5 \\
\hline SNB (degrees) & 79.5 & 79.0 \\
\hline FMA (degrees) & 27.5 & 27.8 \\
\hline U1 to FH (degrees) & 110.5 & 108 \\
\hline Inclination of distal line angle of second molar to SN (degrees) & 64.5 & 65.3 \\
\hline Mini-screw Axis to SN (degrees) & 52.2 & 49.8 \\
\hline Na-Menton distance (mm) & 11.4 & 113 \\
\hline Distal cusp tip of first molar to VR* $(\mathrm{mm})$ & 16.9 & 11.4 \\
\hline
\end{tabular}

*VR: vertical reference line (perpendicular line to occlusal plane from Na point).

\section{DISCUSSION}

In this case report, we evaluated the clinical effectiveness of bone-anchored mini-screw-supported modified Hyrax appliance presented for bodily and en-masse bilateral posterior teeth distalization.

In before-used distalizing methods, anchorage preparations were extraoral anchorage; ${ }^{2}$ occlusal wire rests; palatal acrylic button, for instance, pendulum appliance; skeletal anchorage, such as combination of palatal acrylic button with mini-screw; ${ }^{30}$ and the zygoma anchorage system for buccal segment distalization. ${ }^{34,35,36}$

In distalization appliances, which use first or second premolars for anchorage, reaction forces lead to mesial crown tip of premolars and canines, and finally proclination of incisors. ${ }^{41}$

Extraoral appliances, such as headgear, have no reaction on anterior teeth, but success relies on patient's compliance. Distal crown tipping, extrusion and distal rotation of molars may occur as well. In addition, the force that is applied to patient's neck with the headgear produces a non physiological strain on neck muscles and the cervical spine. ${ }^{33}$

Palatal acrylic button used as anchorage hinders proper oral hygiene. It also applies reactive forces and moments to anterior teeth, and has some contraindications regarding dentition stages and local anatomy. ${ }^{26}$

In bone-anchored devices (osseointegrated implants, titanium mini-screws and mini-plates), most of these complications are solved. The advantages of mini-screws are as follows: no need for osseointegration, more application sites, as well as simple and less aggressive insertion and removal processes. ${ }^{29}$ Many investigations have used them to distalize one molar on each side of the maxilla, but we used mini-screws for bilateral en-masse distalization of all posterior teeth. We used mini-screws in paramedian of anterior palate, with better bone density and thickness relative to buccal cortices. This site does not interfere in root movement, thus eliminating the need for mini-screw transposition during distal driving. This is another advantage of the presented method in comparison to previous ones.

Kaya et al used the zygoma anchorage system to distalize maxillary premolars and molars simultaneously. ${ }^{34}$ Limitations of zygoma-gear appliance are as follows: aggressive insertion and removal surgical procedures, facial inflammation for a number of days after surgery and the possibility of infection. ${ }^{36}$

Backward rotation of the mandible is not usually favorable during distalization; therefore, trying to achieve bodily movement of molars with minimal rotation and distal crown tipping, in addition to suitable case selection according to growth pattern, is important. ${ }^{42}$ Burhan controlled most of these unfavorable changes by night time application of high-pull headgear along with the frog appliance. ${ }^{43}$

For bodily movement, the vector of distalizing force should pass through the center of resistance of the target segments, e.g., heavy rods (power arms) should be used to control the direction of force. ${ }^{25}$ With the Frog appliance, ${ }^{25}$ the Distal Jet, ${ }^{16,17,18}$ the Keles slider, ${ }^{19} \mathrm{Zy}$ goma-Gear Appliance ${ }^{36}$ and Miniscrew Implant Supported Distalization System (MISDS), ${ }^{33,44}$ the force 
vector is approximately at the level of the center of resistance of the first molar. The higher vertical position of the hook on mesially extended transpalatal bar and MI-supported S-sheath makes the line of action of force higher than the center of resistance of the molar segment to set distalizing and intruding molars. ${ }^{38}$

In this study, the appliance was positioned near the palatal vault, $13 \mathrm{~mm}$ apical to the occlusal surface of maxillary molars. The screw was activated once a week, and produced 3.5-mm bodily distal movement of all posterior teeth simultaneously.

The results of a review ${ }^{45}$ revealed that the mean distal movement of maxillary molars was $0.7 \mathrm{~mm}$ per month (range of 0.2-1.2 mm). The slowest rate observed was with the Skeletal Anchorage System (SAS), ${ }^{35,46}$ and the fastest was seen for the Dual-Force Distalizer. ${ }^{37}$ Furthermore, it is likely that comparable overall treatment results can be achieved faster with the SAS rather than with the dual-force distalizer. ${ }^{45}$ In our study, the rate of en-masse distalization was $0.7 \mathrm{~mm}$ per month and faster than enmasse distalization with the SAS system.

The advantages of the method presented in this paper are predictability, good esthetics, immediate force application, bodily en-masse distalization without rotation and tipping of posterior teeth, easily insertion and removal of appliance. The patient did not report any significant pain or discomfort during Hyrax activations.

The appliance can remain until anterior retraction completion as anchorage reinforcement, reducing concerns about relapse. Distalization mostly relapsed through fixed orthodontic therapy, but did not show any significant change in the post-retention period. ${ }^{47}$ Attachment of the appliance at two points in the anterior palate can resist against possible rotational movements of the appliance due to uneven distalization.

The suggestive indications for this mini-screwsupported modified hyrax appliance include: Class II molar relationship, distalization of maxillary posterior teeth in dental maxillary protrusion patients with previous extraction or congenital missing of maxillary premolars, and to provide space for decompensation in pre-surgical orthodontics for severe Class III orthognathic surgical cases with previous extraction of maxillary premolars. ${ }^{35}$

The probable disadvantages of this method include the need for patient's compliance for accurate oral hygiene and screw activation, slight pain during palatal anesthesia (relative to non skeletal anchorage methods), possibility of impingement of appliance components to palatal tissues due to loosening of mini-screws. Nevertheless, the patient reported herein did not have any of them. Previous third molar extraction before molar distalization is another disadvantage of this method.

\section{CONCLUSIONS}

The novel method with mini-screw-supported modified Hyrax appliance presented in this study might be used for bodily, bilateral and en-masse distalization of maxillary posterior teeth without any unwanted movements of anterior teeth. This can reduce treatment duration and expand the orthodontist's potential to provide space and anchorage. 


\section{REFERENCES}

1. Sabri R. Treatment of a severe arch-length deficiency with anteroposterior and transverse expansion: long-term stability. Am J Orthod Dentofacial Orthop. 2010 Mar:137(3):401-11

2. Haas AJ, editor. Headgear therapy: the most efficient way to distalize molars. Semin Orthod. 2000;6(2):79-90

3. Almeida-Pedrin RR, Henriques JF, Almeida RR, Almeida MR, McNamara JA Jr. Effects of the pendulum appliance, cervical headgear, and 2 premolar extractions followed by fixed appliances in patients with Class II malocclusion Am J Orthod Dentofacial Orthop. 2009 Dec;136(6):833-42.

4. Cetlin NM, Ten Hoeve A. Nonextraction treatment. J Clin Orthod. 1983:17(6):396-413.

5. Ferro F, Monsurró A, Perillo Sagittal and vertical changes after treatment of Class II Division 1 malocclusion according to the Cetlin method. Am J Orthod Dentofacial Orthop. 2000 Aug:118(2):150-8

6. Wilson WL, Wilson RC. Multi-directional 3D functional Class II treatment. J Clin Orthod. 1987 Mar:21(3):186-9.

7. Papadopoulos MA, Melkos AB, Athanasiou AE. Noncompliance maxillary molar distalization with the first class appliance: a randomized controlled trial. Am J Orthod Dentofacial Orthop. 2010 May;137(5):586.e1-13; discussion 586-7

8. Fortini A, Lupoli M, Giuntoli F, Franchi L. Dentoskeletal effects induced by rapid molar distalization with the first class appliance. Am J Orthod Dentofacial Orthop. 2004 Jun;125(6):697-704; discussion 704-5.

9. Bondemark L, Kurol J. Distalization of maxillary first and second molars simultaneously with repelling magnets. Eur J Orthod. 1992 Aug;14(4):264-72.

10. Bondemark L. A comparative analysis of distal maxillary molar movement produced by a new lingual intra-arch Ni-Ti coil appliance and a magnetic appliance. Eur J Orthod. 2000 Dec;22(6):683-95.

11. Gianelly AA. Distal movement of the maxillary molars. Am J Orthod Dentofacial Orthop. 1998:114(1):66-72.

12. Locatelli R, Bednar J, Dietz VS, Gianelly AA. Molar distalization with superelastic NiTi wire. J Clin Orthod. 1992 May:26(5):277-9.

13. Haydar S, Uner $O$. Comparison of Jones jig molar distalization appliance with extraoral traction. Am J Orthod Dentofacial Orthop. 2000 Jan;117(1):49-53.

14. Gulati S, Kharbanda OP, Parkash H. Dental and skeletal changes after intraoral molar distalization with sectional jig assembly. Am J Orthod Dentofacial Orthop. 1998 Sept:114(3):319-27.

15. Patel MP, Janson G, Henriques JF, de Almeida RR, de Freitas MR, Pinzan A, et al. Comparative distalization effects of Jones jig and pendulum appliances Am J Orthod Dentofacial Orthop. 2009 Mar:135(3):336-42.

16. Ferguson DJ, Carano A, Bowman SJ, Davis EC, Gutierrez Vega ME, Lee SH. A comparison of two maxillary molar distalizing appliances with the distal jet. World J Orthod. 2005 Winter;6(4):382-90.

17. Chiu PP, McNamara JA Jr, Franchi L. A comparison of two intraoral molar distalization appliances: distal jet versus pendulum. Am J Orthod Dentofacial Orthop. 2005 Sept:128(3):353-65

18. Carano A, Testa M. The distal jet for upper molar distalization. J Clin Orthod. 1996 July:30(7):374-80.

19. Keles A, Pamukcu B, Tokmak EC. Bilateral maxillary molar distalization with sliding mechanics: Keles slider. World J Orthod. 2002;3(1):57-66.

20. Hilgers JJ. The pendulum appliance for Class II non-compliance therapy. J Clin Orthod. 1992 Nov:26(11):706-14.

21. Kinzinger GS, Fritz UB, Sander FG, Diedrich PR. Efficiency of a pendulum appliance for molar distalization related to second and third molar eruption stage. Am J Orthod Dentofacial Orthop. 2004 Jan;125(1):8-23.

22. Kalra V. The K-loop molar distalizing appliance. J Clin Orthod 1995:29(5):298-301

23. Keles A, Sayinsu K. A new approach in maxillary molar distalization: intraoral bodily molar distalizer. Am J Orthod Dentofacial Orthop. 2000 Jan:117(1):39-48

24. Kinzinger G, Fuhrmann R, Gross U, Diedrich P. Modified pendulum appliance including distal screw and uprighting activation for non-compliance therapy of Class II malocclusion in children and adolescents. J Orofac Orthop. 2000;61(3):175-90

25. Bayram M, Nur M, Kilkis D. The frog appliance for upper molar distalization a case report. Korean J Orthod. 2010;40(1):50-60.
26. Kinzinger G, Wehrbein H, Byloff FK, Yildizhan F, Diedrich P. Innovative anchorage alternatives for molar distalization-an overview. J Orofac Orthop. 2005:66(5):397-413.

27. Roberts WE, Marshall KJ, Mozsary PG. Rigid endosseous implant utilized as anchorage to protract molars and close an atrophic extraction site. Angle Orthod. 1990 Summer:60(2):135-52.

28. Byloff FK, Kärcher H, Clar E, Stoff F. An implant to eliminate anchorage loss during molar distalization: a case report involving the Graz implant-supported pendulum. Int J Adult Orthodon Orthognath Surg. 2000 Summer;15(2):129-37.

29. Kircelli BH, Pektaş ZO, Kircelli C. Maxillary molar distalization with a boneanchored pendulum appliance. Angle Orthod. 2006 July;76(4):650-9.

30. Polat-Ozsoy O, Kircelli BH, Arman-Ozçirpici A, Pektaş ZO, Uçkan S. Pendulum appliances with 2 anchorage designs: conventional anchorage vs bone anchorage. Am J Orthod Dentofacial Orthop. 2008 Mar;133(3):339.e9-339.e17.

31. Choi YJ, Lee JS, Cha JY, Park YC. Total distalization of the maxillary arch in a patient with skeletal Class II malocclusion. Am J Orthod Dentofacial Orthop. 2011 Jun;139(6):823-33

32. Escobar SA, Tellez PA, Moncada CA, Villegas CA, Latorre CM, Oberti G Distalization of maxillary molars with the bone-supported pendulum: a clinical study. Am J Orthod Dentofacial Orthop. 2007 Apr:131(4):545-9.

33. Papadopoulos MA. Orthodontic treatment of Class II malocclusion with miniscrew implants. Am J Orthod Dentofacial Orthop. 2008 Nov:134(5):604 e1-16; discussion 604-5

34. Kaya B, Arman A, Uçkan S, Yazici AC. Comparison of the zygoma anchorage system with cervical headgear in buccal segment distalization. Eur J Orthod. 2009 Aug:31(4):417-24.

35. Sugawara J, Kanzaki R, Takahashi I, Nagasaka H, Nanda R. Distal movement of maxillary molars in nongrowing patients with the skeletal anchorage system. Am J Orthod Dentofacial Orthop. 2006:129(6):723-33.

36. Kilkis D, Bayram M, Celikoglu M, Nur M. Unilateral maxillary molar distalization with zygoma-gear appliance. Am J Orthod Dentofacial Orthop. 2012 Aug;142(2):e1-7.

37. Oberti G, Villegas C, Ealo M, Palacio JC, Baccetti T. Maxillary molar distalization with the dual-force distalizer supported by mini-implants: a clinical study. Am J Orthod Dentofacial Orthop. 2009 Mar;135(3):282.e1-5; discussion 282-3.

38. Kyung SH, Lee JY, Shin JW, Hong C, Dietz V, Gianelly AA. Distalization of the entire maxillary arch in an adult. Am J Orthod Dentofacial Orthop. 2009 Apr:135(4 Suppl):S123-32.

39. Keles A, Erverdi N, Sezen S. Bodily distalization of molars with absolute anchorage. Angle Orthod. 2003 Aug;73(4):471-82.

40. Chung KR, Choo H, Kim SH, Ngan P. Timely relocation of mini-implants for uninterrupted full-arch distalization. Am J Orthod Dentofacial Orthop. 2010 Dec;138(6):839-49.

41. Ngantung V. Nanda RS, Bowman SJ. Posttreatment evaluation of the distal jet appliance. Am J Orthod Dentofacial Orthop. 2001 Aug:120(2):178-85

42. Prasad MB, Sreevalli S. Unilateral molar distalization: a nonextraction therapy. Case Rep Dent. 2012;2012:846319.

43. Burhan AS. Combined treatment with headgear and the Frog appliance for maxillary molar distalization: a randomized controlled trial. Korean J Orthod. 2013 Apr:43(2):101-9.

44. Sar C, Kaya B, Ozsoy O, Özcirpici AA. Comparison of two implant-supported molar distalization systems. Angle Orthod. 2013 May:83(3):460-7

45. Fudalej P. Antoszewska J. Are orthodontic distalizers reinforced with the temporary skeletal anchorage devices effective? Am J Orthod Dentofacia Orthop. 2011 Jun;139(6):722-9

46. Cornelis MA, De Clerck HJ. Maxillary molar distalization with miniplates assessed on digital models: a prospective clinical trial. Am J Orthod Dentofacial Orthop. 2007 Sept;132(3):373-7.

47. Caprioglio A, Fontana M, Longoni E, Cozzani M. Long-term evaluation of the molar movements following Pendulum and fixed appliances. Angle Orthod 2013 May;83(3):447-54 